\title{
Revista Serviço Social \& Sociedade: 40 anos contribuindo para o pensamento crítico do Serviço Social brasileiro*
}

\author{
Journal Serviço Social \& Sociedade: 40 years \\ contributing to the critical thinking of the \\ Brazilian Social Work
}

\author{
Raquel Raichelis ${ }^{a}$ \\ (1D) https://orcid.org/0000-0003-3275-3755 \\ Maria Carmelita Yazbek \\ (D) https://orcid.org/0000-0002-4785-472X \\ Mariangela Belfiore Wanderleyc \\ (D) https://orcid.org/0000-0003-3894-6478 \\ Maria Lúcia Martinellid \\ (D) https://orcid.org/0000-0001-9124-2846
}

Resumo: Este texto tem como objetivo realizar uma análise retrospectiva do significado da revista Serviço Social \& Sociedade para o desenvolvimento de um pensamento crítico sobre a profissão e a sociedade brasileira nos seus quarenta anos de existência. Pretendeu evidenciar que sua criação deve ser tributada a um duplo movimento convergente de luta contra a ditadura e de ruptura do Serviço Social com o conservadorismo profissional.

Palavras-chave: Revista Serviço Social \& Sociedade. Serviço Social brasileiro. Pensamento crítico.

\begin{abstract}
This paper aims to conduct a retrospective analysis of the meaning of the journal Social Work \& Society for the development of critical thinking about the profession and Brazilian society in its 40 years of existence. It aimed to show that its creation must be taxed to a double convergent movement of struggle against the dictatorship and of rupture of the Social Work with the professional conservatism.
\end{abstract}

Keywords: Jornal Social Work \& Society. Brazilian Social Work. Critical thinking.

*Texto originalmente publicado na coletânea: Serviço Social no Brasil — história de resistências e de ruptura com o conservadorismo, organizado por Maria Liduina de Oliveira e Silva e publicado pela Cortez Editora em 2016. Para esta edição da revista Serviço Social \& Sociedade, foi revisado e atualizado.

aProfessora do Programa de Estudos Pós-Graduados em Serviço Social da PUC-SP, São Paulo/SP, Brasil.

•Professora e pesquisadora do Programa de Estudos Pós-Graduados em Serviço Social da PUC-SP, São Paulo/SP, Brasil.

‘Faculdade de Ciências Sociais da Pontifícia Universidade Católica de São Paulo (PUC-SP), São Paulo, Brasil.

dPrograma de Pós-Graduação em Serviço Social da Faculdade de Ciências Sociais da PUC-SP, São Paulo, Brasil.

Recebido: 21/5/2019 - Aprovado: 27/5/2019 
À Myriam Veras Baptista, nossa homenagem como principal idealizadora da Revista Serviço Social \& Sociedade

\section{Introdução}

objetivo deste ensaio é apresentar algumas reflexões sobre a contribuição da revista Serviço Social \& Sociedade, que chega a seu número 136, na construção da profissão no Brasil, em estreita e permanente interlocução com o desenvolvimento histórico do Serviço Social, a partir da compreensão de que o fundamento das profissões é a realidade social. Nessa perspectiva, partimos do pressuposto de que a profissão de Serviço Social só pode ser entendida no movimento histórico das classes sociais, como parte integrante das relações sociais na sociedade burguesa, inserindo-se no conjunto da classe trabalhadora e de suas lutas. Assim sendo, no complexo processo de reprodução social da vida, o Serviço Social é parte da divisão social e técnica do trabalho como profissão que tem na questão social e suas contradições na sociedade burguesa a matéria-prima do trabalho profissional. É nesse contexto que também situamos a gênese e o desenvolvimento da revista.

\section{Contexto que dá origem à revista Serviço Social \& Sociedade e os caminhos percorridos}

A revista Serviço Social \& Sociedade veio a público em 1979, em um contexto de grande efervescência social e política. $O$ reaparecimento das lutas operárias no cenário político brasileiro, com as greves metalúrgicas no ABC paulista a partir de 1978, criou as bases para uma inflexão na luta contra a ditadura civil-militar. Era um momento de rearticulação dos movimentos populares sociais de creches, moradia e saúde nas periferias das grandes cidades quando "novos personagens entraram em cena”, parafraseando Eder Sader em seu conhecido livro do mesmo 
nome publicado em 1988. Momento de resistência política, de múltiplos embates, de lutas clandestinas, de retomada de entidades fechadas no período militar e de movimentos em que os trabalhadores enfrentavam a ditadura lutando contra a opressão e o arbítrio. Foi, portanto, nos marcos de ascensão da organização política dos trabalhadores e da luta da sociedade brasileira contra a ditadura que os(as) assistentes sociais se posicionaram coletivamente, por meio de suas entidades representativas, face ao contexto político, econômico e social do país, em uma conjuntura de acirramento político contra a ditadura civil-militar.

Para a profissão de Serviço Social, 1979 foi o ano da "virada", de realização do III Congresso Brasileiro de Assistentes Sociais, pouco antes da decretação da anistia no Brasil e do III Encontro Nacional de Entidades Sindicais que cria a Ceneas (Comissão Executiva Nacional de Entidades Sindicais de Assistência Social). Nesse cenário de lutas, assistentes sociais brasileiros repudiam o conservadorismo da profissão e tornam público seu compromisso com a classe trabalhadora, com a renovação e com a democracia na perspectiva da socialização do poder político, da riqueza e da cultura. Nessa conjuntura emblemática, o coletivo profissional assume a reorganização política das suas entidades representativas em todo o Brasil, a exemplo da Associação Profissional de Assistentes Sociais de São Paulo (Apassp), vinculando-se às lutas classistas e colocando-se no rumo da construção de um projeto profissional de ruptura com o conservadorismo. Configurou-se assim a possibilidade histórica da categoria de assistentes sociais assumir-se enquanto sujeito coletivo na cena política brasileira, em aliança com os demais protagonistas da "virada democrática" no país.

Nesse contexto, em setembro de 1979, antes mesmo da realização do "Congresso da Virada", é publicado o primeiro número da revista Serviço Social \& Sociedade, cuja trajetória caminhou em consonância com a história da profissão e com a profissão na história, suas lutas e avanços, preservando e difundindo sua memória, sua cultura e seu projeto profissional. 
A revista nasceu do diálogo mantido entre a Cortez Editora e um grupo de assistentes sociais, professores(as) da PUC-SP, liderado pela profa. Myriam Veras Baptista, a quem prestamos nossa homenagem neste ensaio.

Até aquele período, o mercado editorial brasileiro na área de Serviço Social era acanhado, com publicações de textos de circulação restrita e traduções de livros em sua maioria norte-americanos, inspirados em autores representativos do Serviço Social clássico, nos termos de Netto (1981b). As publicações latino-americanas das editoras Ecro, Humanitas e do Celats durante os anos de chumbo tinham sua entrada no país controlada e a circulação restrita aos meios acadêmicos em função da censura imposta pela ditadura. Em relação aos periódicos, a única revista de importância nacional - Debates Sociais - , publicada pelo CBCISS desde 1965, expressava a hegemonia conservadora no Serviço Social, funcionalizada pela perspectiva modernizadora-tecnocrática voltada para a instrumentalização técnica de assistentes sociais em resposta às demandas do mercado de trabalho. Vivia-se, portanto, um contexto em que publicar livros e revistas na área configurava-se um desafio político de largo alcance.

Silva (2009, p. 601), em ampla pesquisa realizada em 99 números da revista publicados em três décadas (1979-2009), observa que até o final da década de 1960 a bibliografia do Serviço Social brasileiro publicada por autores nacionais era escassa e se vinculava mais ao campo doutrinário que científico. Por isso pondera que a criação da revista abriu um importante canal para a veiculação de artigos dos pesquisadores da área, cujas produções eram oriundas dos mestrados e posteriormente dos doutorados que se iniciavam no período.

No curso da década de 1980, o Serviço Social brasileiro foi amadurecendo seu projeto profissional de ruptura com o conservadorismo, expressando o leque de tendências políticas críticas à ordem burguesa que ganham legitimidade para expressar-se mais abertamente. 
Netto (1996, p. 111), ao referir-se à ambiência profissional do período, observa que:

É correto afirmar-se que, ao final dos anos oitenta, a categoria profissional refletia o largo espectro das tendências ideopolíticas que tensionam e animam a vida social brasileira. Numa palavra, democratizou-se a relação no interior da categoria e legitimou-se o direito à diferença ideopolítica. Nunca será exagerada a significação dessa conquista, num corpo profissional em que o doutrinarismo católico inseriu, originariamente, uma refinada e duradoura intolerância.

A revista acompanhou a democratização e o amadurecimento intelectual e ideopolítico do Serviço Social, constituindo-se ao longo das décadas seguintes num importante veículo da produção teórica brasileira, impulsionada pelos programas de pós-graduação que se multiplicam na área e estimulam a constituição de intelectuais especialmente dedicados ao ensino e à pesquisa nas diferentes regiões do país, fato inédito em uma área reconhecida pelas dimensões interventiva e executiva. Ao mesmo tempo, é partícipe e indutora dos processos de diferenciação social experimentados pela profissão em que se destacam a laicização e o pluralismo.

A laicização é expressão da renovação do Serviço Social brasileiro a partir da crise do Serviço Social tradicional (Netto, 1990, impulsionada pelas novas demandas sociais e contradições abertas pela modernização conservadora instaurada pelo ciclo ditatorial no país. A reorganização do Estado capitalista sob a égide dos monopólios e de suas respostas ao agravamento da questão social, por meio das políticas sociais, criam novas exigências para o trabalho institucional, para a formação profissional e para o desenvolvimento da pesquisa na área do Serviço Social.

Trata-se de um cenário de ampliação e nacionalização do mercado de trabalho profissional, universalização do assalariamento, mudanças no perfil do alunado oriundo agora das camadas médias urbanas assalariadas, incorporação do Serviço Social ao espaço acadêmico e à 
universidade pública, interlocução com as ciências sociais e com novas teorias sociais. Dinâmica profissional que revela a insuficiência do doutrinarismo católico para processar as novas requisições profissionais e que estimulará, de um lado, a refuncionalização neopositivista do Serviço Social e, de outro, a aproximação do Serviço Social com o marxismo que a partir desse momento, mesmo com todos os limites dessa relação inicial, irá polarizar o debate profissional, quebrando a hegemonia conservadora que prevalecia até então.

É, portanto, nesse contexto de diferenciação interna do meio profissional e de interlocução acadêmica mais ampla que se instaura o pluralismo teórico e político no Serviço Social, estimulador do debate, da disputa de projetos e das polêmicas teórico-metodológicas presentes na categoria, em um movimento que busca sintonizar o Serviço Social com temas e demandas que afetam a vida da classe trabalhadora e os rumos da questão social.

Reafirmando a clássica análise de Coutinho no Caderno Abess n. 4 (1991, p. 11), "um pluralismo que se articule com hegemonia, respeitando as diversidades e alimentando-se dessas diversidades". Disputa que no âmbito epistemológico e do pensamento social, ainda segundo o mesmo autor, envolve o enfrentamento do ecletismo ou relativismo, tornando-se absolutamente necessário o debate de ideias, o confronto entre as diferentes posições teóricas, a busca da "verdade" que significa o esforço de fazer com que a teoria se aproxime o máximo possível do real.

O significado da criação da revista Serviço Social \& Sociedade ganha inteligibilidade se situado nesse contexto de abertura ao debate de ideias, com base na premissa de que, como adverte Coutinho (1991, p. 14),

no terreno do pensamento social não existe apenas a ciência, mas também o mundo dos valores, o conjunto de concepções de mundo, as quais implicam não só a representação daquilo que é, mas também, e sobretudo, daquilo que deve ser. 
A própria composição do primeiro Conselho Editorial da revista é expressão inequívoca do pluralismo como expressão da convivência e respeito às diferenças políticas num momento de deslocamentos hegemônicos na disputa de projetos profissionais, sem incorrer no ecletismo teórico ou no relativismo moral, mas exercitando a busca da unidade na diversidade.

A revista buscou assumir-se desde as origens como um espaço de debate plural e democrático, que pudesse expressar o confrontamento e a livre manifestação de ideias e posições existentes na categoria profissional, com uma direção social comprometida com a construção de um projeto profissional radicalmente crítico e emancipador, como expõe o editorial do primeiro número lançado em setembro de 1979, do qual extraímos o seguinte trecho:

Assim nasceu a revista: da esperança de alguns, do esforço de outros e sobretudo da cooperação de todos aqueles que acreditam no esforço coletivo como forma de atingir objetivos. Trata-se de uma revista pluralista, aberta, crítica, geradora do debate, fundamentada mesmo no exercício democrático da liberdade... Desencadear um amplo processo de reflexão e de debate dentro da categoria profissional sobre questões básicas do Serviço Social, contribuir para o fortalecimento da categoria profissional incentivando a reflexão, a crítica e o confrontamento de posições, são também objetivos buscados por Serviço Social \& Sociedade.

Desde o início, a revista definiu como público prioritário o amplo espectro de assistentes sociais e profissionais de áreas afins, alcançando também professores, graduandos, pós-graduandos e pesquisadores, abrindo-se para o diálogo com outras áreas de conhecimento e repercutindo, também, o pensamento de suas entidades representativas. Nessa direção estabeleceu, como direcionamento de seu projeto editorial, que se mantém vivo até os dias atuais, dar visibilidade à produção acadêmica e profissional de assistentes sociais e pesquisadores das ciências sociais e humanas, contribuindo para o debate e o aprofundamento crítico da 
teoria social, nos marcos da direção estratégica que fundamenta o projeto ético-político profissional do Serviço Social (denominação posterior ao assim chamado projeto de ruptura), em estreito diálogo com a realidade brasileira e latino-americana.

Destaca-se aqui o compromisso sempre presente de tratar temas e demandas profissionais dos diferentes espaços sócio-ocupacionais em que atuam os(as) assistentes sociais, problematizando seus fundamentos a partir de uma perspectiva que contribua para a compreensão teórico-crítica de seu significado e possibilidades de enfrentamento, fortalecendo valores que alimentem a cultura profissional radicalmente democrática e emancipatória. Uma releitura dos "olhos de capa" e eixos temáticos da série histórica que atravessa as diferentes décadas pode testemunhar essa pulsação da revista com o movimento histórico da sociedade e da profissão, em alguns momentos antecipando e prospectando tendências e polêmicas. Entre elas cabe destacar, pela significação que assumiu na época, o memorável debate travado nas páginas da revista entre Helena Iracy Junqueira e José Paulo Netto acerca do Movimento de Reconceituação do Serviço Social na América Latina. ${ }^{1}$

Desde o primeiro número da revista havia a preocupação de que fosse também um veículo de comunicação sobre eventos importantes da categoria profissional, no Brasil e na América Latina, especialmente, e dele constava a informação sobre o IX Seminário Latino-americano de Serviço Social, realizado na Venezuela em 1979. No decorrer de sua trajetória, seções foram criadas e recriadas de modo a responder às expectativas e necessidades dos seus leitores, captadas pelo Conselho Editorial. Para exemplificar destacamos a seção Trocando em Miúdos, onde foram publicados verbetes referentes a conceitos ou categorias teóricas assinados por autores de reconhecido domínio nas temáticas; Canal Aberto, espaço criado para fomentar o diálogo entre a editora e

\footnotetext{
Referimo-nos aos artigos de Junqueira: "Quase duas décadas de reconceituação do Serviço Social - uma abordagem crítica”, e de Netto: "A crítica conservadora à reconceptualização", publicados respectivamente nos números 4 de 1980 e 5 de 1981.
} 
os leitores; e a seção Informe-se, com o objetivo de comunicar eventos e datas comemorativas relevantes. Além destas foram sendo introduzidas e integram a estrutura da revista até o presente momento as seções móveis que são veiculadas de acordo com a composição de cada número: Expressões do Pensamento Social, Comunicação de Pesquisa, Depoimento, Entrevista, Homenagem, Polêmicas, Registro, Relato de Experiência, Resenha e Temas para Debate.

O primeiro Conselho Editorial da revista teve significativa representação acadêmica com a prevalência de professores da PUC-SP. Tal fato se explica, a nosso ver, pela conjuntura da época em que a revista foi criada, quando havia um vazio teórico na produção nacional e a PUC-SP, que criara naquela década o primeiro mestrado em Serviço Social do Brasil e se preparava para inaugurar seu doutorado, mobilizava-se para a construção e a disseminação do conhecimento que vinha sendo elaborado na área. Buscou, então, agregar um grupo de professores que pudesse levar à frente um projeto de revista de âmbito nacional que refletisse sobre os desafios do Serviço Social face ao momento histórico, numa parceria com a Cortez Editora, que, como já foi dito, abraçou esse desafio. ${ }^{2}$

Já no seu sétimo número (dezembro de 1981), a revista apresentou seu primeiro Conselho de Colaboradores, constituído por docentes dos vários estados brasileiros. O objetivo era a sua disseminação por meio desses divulgadores em seus estados, bem como o incentivo à produção de artigos de autores de várias regiões do país.

Em curto espaço de tempo a revista ganhou a contribuição de intelectuais, profissionais e docentes de diferentes instituições de ensino superior, contando inclusive com a ampliação de seu Conselho Editorial, que passou a incorporar nomes expressivos nacionais e do exterior.

Tal compromisso, que mobilizou um grupo de professores da PUC-SP com a criação da revista Serviço Social \& Sociedade e que se estende até o presente, representado pelas autoras deste ensaio, explica a nosso ver as razões pelas quais a área de Serviço Social da PUC-SP não optou por criar um periódico próprio. 
Em seu n. 50 (abril de 1996) registra-se importante atualização do Regimento do Conselho Editorial no que se refere a atribuições e competências, dinâmica de renovação de seus membros, processo de avaliação de artigos, dentre outros, e é anunciada a criação do Grupo de Colaboradores, composto por um representante de cada unidade de ensino de Serviço Social do país (47 docentes), com o objetivo de somar esforços para captar e disseminar a produção teórica da área, de modo que fosse mais ampla e representativa. $\mathrm{Na}$ impossibilidade de a Cortez Editora contar em seu Conselho com vários membros de outros estados (por questões financeiras e operacionais), constituía-se assim um importante elo da revista com cada unidade de ensino, ao mesmo tempo em que também eram divulgados os livros da área enviados gratuitamente aos colaboradores assim que publicados pela Cortez. Ao grupo de colaboradores nacionais juntaram-se os internacionais, docentes de universidades latino-americanas (Argentina, Colômbia, Costa Rica, Guatemala, México, Paraguai, Porto Rico, Uruguai, Venezuela) e europeias (Portugal e Espanha).

Um passo significativo que certamente marcou uma nova etapa para o periódico foi a sua indexação em base de dados internacional, o que exigiu a ampliação e a diversificação do corpo editorial. Foi constituído, então, o Conselho Ampliado integrado por membros de vários estados brasileiros e colaboradores internacionais.

A indexação da revista pelo Scielo deu-se em 2010, cujo primeiro número dessa nova fase (n. 105) foi publicado em março de 2011, exigiu do Conselho Editorial um intenso processo de reorganização e adaptações frente às inúmeras exigências apresentadas na época e renovadas em 2015. O periódico, agora on-line, facilitou o acesso ao público interessado, porém gerou, como era de se esperar, uma queda das assinaturas, demandando a internalização do impacto financeiro pela editora e mobilizando o Conselho Editorial e todos os colaboradores comprometidos com sua continuidade. A classificação da revista no Estrato A1 (o mais alto) no sistema Qualis Periódicos da Capes/MEC veio consolidar o seu reconhecimento acadêmico na área do Serviço Social, renovar o desafio 
de manter o alto nível de qualidade alcançado e continuar ocupando um lugar de destaque no cenário editorial em nível nacional e internacional, como vem fazendo há quase quatro décadas ininterruptamente.

\section{Marcos e marcas da revista Serviço Social \& Sociedade - quatro décadas de história comprometida com a profissão}

Alguns números da revista representam marcos que deixaram sinais relevantes e que nos ajudam a entender seu papel e sua importância, expressando também a contribuição da Cortez Editora aos avanços da direção estratégica do projeto profissional do Serviço Social brasileiro. Merecem especial destaque as mesas-redondas promovidas pelo próprio Conselho Editorial, bem como aquelas que marcaram momentos significativos na trajetória da revista e especialmente da própria sociedade brasileira.

Tomando por referência a primeira década da revista, de 1979 a 1989, podemos afirmar que foram anos de maturação, de consolidação de um espaço crítico, reflexivo, articulador da produção teórica de assistentes sociais e de profissionais e pesquisadores de áreas correlatas.

Foi, também, uma década da maior importância para o Serviço Social brasileiro, quando assume o marxismo como referência analítica, tornando hegemônica a abordagem da profissão como componente da prática social coletiva, inserida na dinâmica das relações sociais e participando do processo contraditório de reprodução dessas relações.

Desde seu nascedouro, a revista expressa sua permanente interlocução com a história, buscando dialogar com os rumos da conjuntura econômica, política e cultural e contribuir para seu desvendamento crítico por meio de destacados analistas e pesquisadores, abrindo, inclusive, espaço para estudantes, lideranças populares e entidades representativas.

Contemporânea que foi, em sua gênese, do importante movimento de renovação do Serviço Social brasileiro no contexto do Movimento de 
Reconceituação latino-americano, contribuiu e vem contribuindo sistematicamente com o desenvolvimento acadêmico e profissional do Serviço Social e de áreas afins. A sensibilidade com as questões presentes na sociedade naquele momento histórico fez com que a revista assumisse um protagonismo em relação a temáticas relevantes no debate social e profissional da época.

Exemplo significativo é a mesa-redonda sobre a história do Serviço Social no Brasil, realizada em 22 de novembro de 1982 na Reitoria da Pontifícia Universidade Católica de São Paulo, contando com a participação de notáveis pioneiros da profissão: Francisco de Paula Ferreira, Helena Iracy Junqueira, José Pinheiro Cortez e Nadir Gouvêa Kfouri, então reitora da PUC-SP. Organizada como parte das comemorações dos cinquenta anos do Serviço Social no Brasil, com vistas à publicação na revista de n. 12 de agosto de 1983, a mesa ensejou posteriormente um rico debate entre os conselheiros: Aldaíza de Oliveira Sposati, Luiza Erundina de Souza, Maria Carmelita Yazbek, Mário da Costa Barbosa, Myrian Veras Baptista, Raquel Raichelis e Sérgio Fuhrmann. No seu editorial, essa fecunda contribuição está devidamente registrada, a partir dos eixos que a caracterizaram: 1) A história do Serviço Social e o Serviço Social na história; 2) A prática da assistência na história do Serviço Social.

Desnecessário dizer o quanto essas questões fecundaram importantes debates na profissão e o quanto permanecem atuais e presentes nos diferentes fóruns acadêmicos, científicos e organizativos da categoria profissional. Com toda cautela exigida, é possível afirmar que aí estão presentes as raízes seminais do novo currículo para o curso de Serviço Social que viria a ser implantado na década seguinte.

Em abril de 1989, ao completar dez anos de circulação ininterrupta em todo o território nacional, já se constituindo num significativo espaço propulsor do debate e da produção teórica, em edição comemorativa de uma década de sua existência, nova mesa-redonda é realizada com os membros do Conselho, com o objetivo de revisitar a sua trajetória histórica e identificar momentos significativos, em estreita articulação com a dinâmica societária e profissional. 
Cabe registrar as palavras do editor, José Xavier Cortez, nas páginas iniciais da revista n. 30:

Estamos conscientes de que os 10 anos da revista Serviço Social \& Sociedade significam uma contribuição concreta ao debate e à transformação que vêm ocorrendo na sociedade com a participação efetiva do assistente social.

Ressalta, ainda, o crescimento das publicações na área, constituindo um acervo razoável de obras publicadas, além do reconhecimento do papel pioneiro da editora, a primeira a acreditar no potencial teórico do Serviço Social, publicando suas primeiras dissertações de mestrado, e a investir num trabalho comprometido com as lutas sociais, revelando contradições e conflitos para a construção de uma sociedade democrática.

Com efeito, estamos nos referindo à década fundamental na história do país, pois a sociedade civil brasileira começava a se reorganizar politicamente. É um novo contexto político, de protagonismo dos movimentos sociais, dos partidos políticos, das organizações sindicais e classistas. No âmbito da própria categoria profissional, o campo da esquerda adquire visibilidade, alinhando-se com as lutas mais gerais do povo brasileiro.

Cumprindo sua vocação inicial pluralista e estimuladora do debate coletivo, a revista abriu um amplo espaço de manifestação para assistentes sociais brasileiros(as) e latino-americanos(as), o que representou uma conquista das mais importantes em termos de fortalecimento da categoria profissional.

Vale ressaltar que a aproximação com a América Latina se fortaleceu muito nesse período, especialmente com seus organismos acadêmicos mais representativos, como o Centro Latino-Americano de Trabalho Social (Celats), instituindo-se aí uma parceria de longa duração que se estendeu também para algumas universidades, em uma fase de expansão da pós-graduação no Brasil, o que favorecia em muito esse nível de intercâmbio.

Dessa parceria, ampliada também para os fóruns organizativos da categoria profissional, nasce a proposta original de construção da 
Biblioteca Latino-Americana de Serviço Social, que iria se concretizar na década seguinte, marcando a presença da produção teórica brasileira em todo o continente.

No âmbito acadêmico é indispensável ressaltar que é nesse período que se estreitam as relações entre a Pontifícia Universidade Católica de São Paulo e a Universidade Nacional de La Plata, Argentina, com vistas à implantação de um curso de pós-graduação em Serviço Social. Um primeiro passo nesse sentido foram os trâmites junto às autoridades educacionais argentinas para o reconhecimento do grau acadêmico-científico do Serviço Social, possibilitando que assistentes sociais se inserissem na carreira docentes e de pesquisa. Em outubro de 1995, celebra-se o convênio entre as universidades iniciando-se então o curso de pós-graduação, o que permitiu a consolidação de novas bases identitárias para o Serviço Social argentino e, particularmente, para a Escola de Serviço Social que, em 2005, adquire novo status acadêmico de faculdade.

A Cortez Editora participou de todos esses momentos, colaborando com o enriquecimento do acervo da biblioteca da universidade e com sua presença nos principais eventos realizados no período, tendo ainda acolhido e publicado a produção acadêmica decorrente dessa pós-graduação. Outro resultado muito concreto foi o intercâmbio estabelecido com os docentes e pesquisadores argentinos que participam ainda hoje dos conselhos editoriais e científicos da revista.

Ao longo dos anos 1980, a Pontifícia Universidade Católica de São Paulo já mantinha Acordo de Intercâmbio com Portugal, especialmente Lisboa, Porto e Coimbra, o que possibilitou a reaproximação do Serviço Social brasileiro com o português e a presença de assistentes sociais portugueses no número comemorativo dos dez anos da revista.

Esse acordo, vigente no período de 1986 a 2004, teve uma importância crucial na história do Serviço Social português, pois exerceu um papel decisivo para o reconhecimento do grau acadêmico de nível superior para o curso de Serviço Social daquele país. Contribuiu ainda decisivamente para a regulamentação da profissão e inserção de professores(as) e pesquisadores(as) na carreira científica portuguesa. 
Assim, além de formar os primeiros mestres e doutores em Serviço Social, o convênio, realizado com a intermediação das agências de pesquisa e fomento do Brasil e de Portugal, permitiu que fossem institucionalizados os cursos de pós-graduação em Serviço Social nos institutos de Lisboa, Porto e Coimbra, além de incentivar a criação do Centro Português de Investigação e História do Trabalho Social.

Como ocorreu na Argentina, a editora teve igualmente uma significativa presença em Portugal, acolhendo a produção das dissertações e teses dos primeiros mestres e doutores e criando intensos laços de intercâmbio que perduram até hoje, seja por meio das publicações na revista e/ou livros da editora, ou da participação em seus conselhos editoriais e científicos. Vale menção à mesa-redonda organizada pelas profas. Myriam V. Baptista e Maria Lúcia Martinelli na Universidade Nacional de La Plata, publicada na revista n. 51 de agosto de 1996. A partir desse intercâmbio, a editora marca sua aproximação com os países africanos de língua portuguesa, que se intensificou nas décadas seguintes.

Revisitando esse período, pode-se afirmar que a revista, sempre atenta ao seu compromisso com os avanços do Serviço Social como profissão e área de conhecimento, cumpriu seu objetivo estratégico de contribuir para o adensamento teórico e político das bases fundantes do Projeto Ético-Político profissional, bem como para o reconhecimento do caráter público e da dimensão ética do trabalho de assistentes sociais.

A revista n. 50, publicada em abril de 1996, com o "olho de capa" "O Serviço Social no século XXI", obteve grande acolhida do público leitor, constituindo-se em um marco pela importância dos artigos que veiculou, além de inaugurar a presença da nova assessora editorial da área de Serviço Social, na Cortez Editora, a assistente social Elizabete Borgianni, a quem também homenageamos neste ensaio, pela relevância de sua contribuição profissional e política para os avanços não apenas da revista, mas do conjunto das publicações da área.

Neste número é veiculada nova mesa-redonda promovida pelo Conselho Editorial, que teve como temática os caminhos da profissão e 
o Serviço Social no século XXI. O debate foi marcado pela expressão da complexidade da conjuntura naquele momento, das transformações no mundo do trabalho e das contradições presentes na discussão das políticas sociais, especialmente da política de assistência social, envolvendo complexas dinâmicas societárias, tanto políticas como profissionais.

Destacavam os debatedores, com veemência, a necessidade de conferir àqueles movimentos organicidade política e profissional, ao mesmo tempo em que era preciso contribuir para instrumentalizar criticamente a prática profissional e política. Reafirmou-se a luta pelos direitos sociais, a questão do compromisso com a qualidade dos serviços sociais públicos, a defesa da democracia, com destaque para a conduta ética do profissional, recolocando a questão dos valores no Serviço Social. Mais uma vez os embates presentes na categoria profissional se expressaram no confronto de posições entre os próprios membros do Conselho, que não se furtaram a expor suas divergências e convergências próprias do debate plural que caracterizava a sua convivência.

É interessante notar que estávamos em meados da década de 1990, e a revista abriu importante espaço para a veiculação de artigos que expressavam o debate e as polêmicas envolvendo a política de assistência social. É desse período a realização da I Conferência Nacional de Assistência Social quando o Serviço Social foi chamado a se posicionar como protagonista inserido criticamente nesse processo. Vivia-se um momento de avanço expressivo do projeto neoliberal, demandando da categoria profissional novas respostas e mobilização coletiva.

Cabe ainda uma última menção à revista n. 100, pela importância dessa edição comemorativa dos trinta anos de sua existência, juntamente com os trinta anos do "Congresso da Virada", marcando a viagem de volta às origens, ressignificando memórias e trajetórias, mas agora com a distância crítica necessária para a acurada reflexão não apenas sobre o seu significado histórico, mas também sobre seus rebatimentos posteriores e o legado às futuras gerações profissionais. Nova mesa-redonda foi realizada em 28 de agosto de 2009 nas dependências da PUC-SP, com 
a presença de professores(as) e pesquisadores(as) de várias regiões do Brasil e entidades da categoria, permitindo trazer à memória momentos marcantes da história do Serviço Social brasileiro, com destaque para o “Congresso da Virada”, do qual a revista é indissociável.

Esse mesmo número contém o artigo de Maria Ozanira da Silva e Silva sobre os "Trinta anos da Revista Serviço \& Social e Sociedade e sua contribuição para o desenvolvimento do Serviço Social no Brasil”, resultado de ampla pesquisa desenvolvida nos números publicados durante três décadas. Objetivou "situar a revista e o Serviço Social no processo histórico da construção da sociedade brasileira, ambos, revista e profissão, se gestando e se desenvolvendo no âmbito das relações sociais" (p. 600). O levantamento realizado computou um total de 925 publicações envolvendo as diferentes seções, com um importante crescimento no período de 2000-9, além da desconcentração da autoria dos artigos na mesma década, evidenciando "o caráter democrático e plural da revista Serviço Social \& Sociedade por oportunizar a divulgação do conhecimento produzido sobre o Serviço Social brasileiro para além da academia" (p. 606).

A análise sobre as temáticas publicadas pela revista demonstrou sua sintonia com as expressões da questão social e as demandas profissionais e políticas do Serviço Social e da sociedade brasileira, reafirmando compromissos com as necessidades sociais e demandas da classe trabalhadora articuladas ao projeto profissional e ao projeto emancipatório que o fundamenta. Temas voltados para a construção teórico-metodológica, técnico-operativa e ideopolítica e um conjunto de reflexões sobre as relações do Serviço Social com as políticas públicas e seus usuários compareceram em inúmeras edições, com distintas abordagens e autorias. Análises entrelaçadas com o movimento estrutural e conjuntural da sociedade brasileira, com destaque para o Estado, a globalização e o neoliberalismo e com dinâmicas relacionadas à reestruturação produtiva, transformações no mundo do trabalho, violência e pobreza, fundamentais para o desvelamento crítico dos desafios enfrentados 
pelo trabalho profissional nos diferentes espaços sócio-ocupacionais. 0 balanço realizado pela referida pesquisa evidenciou que temas relativos às transformações societárias, no campo da economia, da cultura e da ideologia, foram amplamente tratados face ao imperativo de se repensar o Projeto Ético-Político Profissional, reafirmando sua base teórica centrada na tradição marxista, sem excluir o debate com outras matrizes teóricas.

\section{A revista Serviço Social \& Sociedade nos marcos do neoliberalismo em crise: projeções futuras}

Reafirmando o significado da revista Serviço Social \& Sociedade no cenário editorial da profissão, não é demais afirmar que se trata do único periódico de circulação nacional na área com veiculação ininterrupta e regular desde 1979, mantendo-se como um dos mais importantes canais de consulta obrigatória de docentes e estudantes, de pesquisadores e profissionais que buscam sintonizar-se com o debate dos grandes temas nacionais e internacionais que incidem no Serviço Social e nas ciências humanas e sociais. $O$ dado novo é que a categoria profissional pode contar não apenas com essa histórica revista, mas também com um conjunto amplo e diversificado de periódicos de qualificação crescente, o que torna o cenário editorial do Serviço Social brasileiro mais rico, diverso e plural, mas no qual uma revista publicada por uma editora comercial, como é o caso desta, se ressente da crise que invade o mercado editorial brasileiro em geral.

Os caminhos da revista seguirão em um cenário cada vez mais complexo e, de certa forma sombrio para a sociedade brasileira e para o Serviço Social. A questão social vem assumindo novas configurações e expressões em um mundo globalizado pelo capital financeiro, pelos interesses das grandes corporações, das mídias, do conhecimento planetarizado, saturado, instrumentalizado e a serviço do grande capital. No Brasil de 2019, em uma conjuntura política de retrocessos democráticos e obscurantismo civilizatório, a profissão é interpelada e desafiada a 
construir ações de resistência e alianças estratégicas no jogo da grande política, buscando decifrar os rumos da realidade onde se insere.

Nesse contexto, é cada vez mais evidente que diferentes projetos sociopolíticos da profissão ampliarão seu confronto. O projeto neoconservador, valendo-se de novas roupagens, focalizará cada vez mais análises e ações, apelando para a microintervenção, para as relações interpessoais, para respostas imediatas às demandas do mercado de trabalho. Processos que se desconectados de análises sobre as dinâmicas das relações capitalistas na sociedade brasileira poderão conduzir a uma desqualificação da direção social estratégica do projeto profissional, "levando [mais] água para o moinho do conservadorismo", nas palavras de Netto (1996, p. 118).

Como vimos analisando ao longo deste ensaio, dado o entrelaçamento dos rumos da profissão e os caminhos da revista, certamente muitos desafios se colocam para que esse periódico permaneça contribuindo para o desvelamento dos processos societários que fundam a hegemonia do grande capital e rebatem nas novas manifestações da questão social, no espaço de reestruturação das políticas sociais públicas, no crescimento do terceiro setor, em processos e dinâmicas que trazem para a profissão temáticas emergentes e novos (e históricos) sujeitos sociais.

O desafio maior da revista consiste, portanto, em permanecer ativa nos debates e embates da profissão, renovando a legitimidade conquistada junto ao seu público leitor, mantendo o compromisso com o desenvolvimento intelectual e cultural da categoria profissional, na perspectiva acumulada pela direção social estratégica do Projeto Ético-Politico, sem descuidar do contingente de assistentes sociais que, na atualidade, encontra-se cada vez mais subsumido aos constrangimentos do mercado de trabalho, precarizado e intensificado, bem como à massificação de informações não raro inidôneas (as chamadas fake news), veiculadas maciçamente pelas mídias e redes digitais.

É fundamental manter viva e cada vez mais disseminada a circulação de informações confiáveis e consistentes, que contribuem para o aprofundamento analítico de dimensões não explicitadas da crise contemporânea 
e das suas consequências, objetivando, como afirma Iamamoto (1982), decifrar as lógicas do capitalismo contemporâneo e as dimensões éticas, políticas, culturais de uma sociedade em acelerada mudança.

Impõem-se ainda à revista a ampliação da interlocução internacional, a aproximação cada vez mais sólida com centros de formação e pesquisa e com organizações profissionais e políticas do campo progressista, em sintonia fina com o enfrentamento dos dilemas do trabalho profissional para continuar existindo como espaço vivo de produção teórico-crítica, aberto às novas e desafiantes questões contemporâneas que interpelam a realidade profissional e acadêmica, buscando perfilar-se junto ao movimento coletivo de resistência à hegemonia neoliberal em crise.

Sem pretendermos minimizar a magnitude dos desafios a ser enfrentados, anima-nos a certeza de que as contradições e a negatividade desencadeadas pelo movimento social constituem o fermento necessário para as rupturas, que por sua vez não se fazem sem disputas e resistências de sujeitos coletivos. Em tal contexto, espaços de difusão do pensamento comprometido com um projeto societário emancipatório e igualitário, como a revista Serviço Social \& Sociedade, com certeza são estratégicos e precisam ser preservados e continuamente renovados, contribuindo para o adensamento de um conhecimento solidamente fundamentado na teoria crítica sobre o Serviço Social e a sociedade brasileira.

\section{Referências}

COUTINHO, Carlos Nelson. Pluralismo: dimensões teóricas e políticas. Cadernos ABESS, São Paulo, n. 4, p. 5-17, 1991.

EDITORIAL. Serviço Social \& Sociedade, São Paulo, n. 1, p. 3, 1979.

IAMAMOTO, Marilda V. Relações sociais e Serviço Social no Brasil: esboço de uma interpretação sociológica da profissão. São Paulo: Cortez, 1982.

NETTO, José Paulo. Capitalismo monopolista e Serviço Social. São Paulo: Cortez, 1981a. A crítica conservadora à reconceptualização. Serviço Social \& Sociedade, São Paulo, n. 5, p. 59-75, 1981b. 
NETTO, José Paulo. Transformações societárias e Serviço Social - notas para uma análise prospectiva da profissão no Brasil. Serviço Social \& Sociedade, São Paulo, n. 50, p. 87-132, 1996.

SILVA, Maria Ozanira da Silva e. Trinta anos da revista Serviço Social \& Sociedade: contribuições para a construção e o desenvolvimento do Serviço Social no Brasil. Serviço Social \& Sociedade, São Paulo n. 100, p. 599-649, 2009.

\section{Sobre as autoras}

Raquel Raichelis Degenszajn - Assistente social, doutora em Serviço Social. E-mail: raichelis@uol.com.br

Maria Carmelita Yazbek - Assistente social, doutora em Serviço Social. E-mail:mcyaz@uol.com.br

Mariangela Belfiore WANDerley - Assistente social, professora associada do Departamento de Política e Gestão. Docente do Programa de Pós-Graduação em Serviço Social.

E-mail: mariangela.belfiore@gmail.com

Maria Lúcia Martinelli - Assistente social, doutora em Serviço Social. E-mail: mlmartinelli@terra.com.br 